\title{
Laugh syncope as a rare sub-type of the situational syncopes: a case report Katsufumi Nishida ${ }^{1}$, Sean K Hirota ${ }^{2}$ and Jinichi Tokeshi*1
}

Address: ${ }^{1}$ Department of Medicine, John A Burns School of Medicine, University of Hawaii, Honolulu, HI, USA and ${ }^{2}$ John A Burns School of Medicine, University of Hawaii, Honolulu, HI, USA

Email: Katsufumi Nishida - knishida1026@ybb.ne.jp; Sean K Hirota - skhirota@yahoo.com; Jinichi Tokeshi* - jinichi.tokeshi@gmail.com

* Corresponding author

Published: 7 June 2008

Journal of Medical Case Reports 2008, 2:197 doi:10.1 186/1752-1947-2-197

Received: 27 December 2007

Accepted: 7 June 2008

This article is available from: http://www.jmedicalcasereports.com/content/2/I/197

(c) 2008 Nishida et al; licensee BioMed Central Ltd.

This is an Open Access article distributed under the terms of the Creative Commons Attribution License (http://creativecommons.org/licenses/by/2.0), which permits unrestricted use, distribution, and reproduction in any medium, provided the original work is properly cited.

\begin{abstract}
Introduction: Laughter is a good medicine; it enhances cardiovascular health and the immune system. What happens, however, if a person laughs too much or the laughter becomes out of control? Laughter-induced syncope is rare and likely goes unrecognized by many health care providers. It is thought to be another form of Valsalva-induced syncope.

Case presentation: We report the case of a 56-year-old, moderately obese (body mass index of 35) man with a past medical history of sleep apnea, hypertension and hyperlipidemia who suffered from syncope secondary to intense laughter. The patient also had a history of syncope in the distant past when he collapsed on the floor for several seconds. Treadmill stress testing after the incident revealed no arrhythmia or ischemic disease, although he complained of dizziness after the test and a sudden drop in blood pressure was noted.
\end{abstract}

Conclusion: Laughter-induced or gelastic syncope is extremely rare. It is thought to be a sub-type of the situational syncopes.

\section{Introduction}

Syncope is a transient loss of consciousness and postural tone secondary to inadequate cerebral perfusion that spontaneously resolves without medical intervention. It is a relatively common clinical problem accounting for $1 \%$ to $1.5 \%$ of emergency department visits and around $6 \%$ of hospital admissions annually [1]. However, syncope remains a diagnostic challenge for clinicians, as the differential diagnosis is extensive (Table 1). Among the various classifications, neurally mediated, cardiac and unexplained etiologies appear to be the most common diagnoses. In a prospective study of 341 patients presenting with syncope, a cardiac cause of syncope was established in $23 \%$ of the patients, a neurally mediated cause in $58 \%$ and the cause of syncope remained unexplained in $18 \%$ [2].

Laughter-induced or gelastic (derived from the Greek word for laughter, 'gelos') syncope is extremely rare. It is a sub-type of the situational syncopes hypothesized to be the result of a neurally mediated reflex triggered by increased intrathoracic pressure. Intense laughter causes repetitive forced expirations in a staccato pattern with a Valsalva-type effect. The associated increase in intrathoracic pressure reduces venous return resulting in decreased cardiac output and a transient reduction in cerebral perfusion. It has also been proposed that strenuous laughter might produce isometric muscle contraction resulting in 
Table I: Classification of syncope

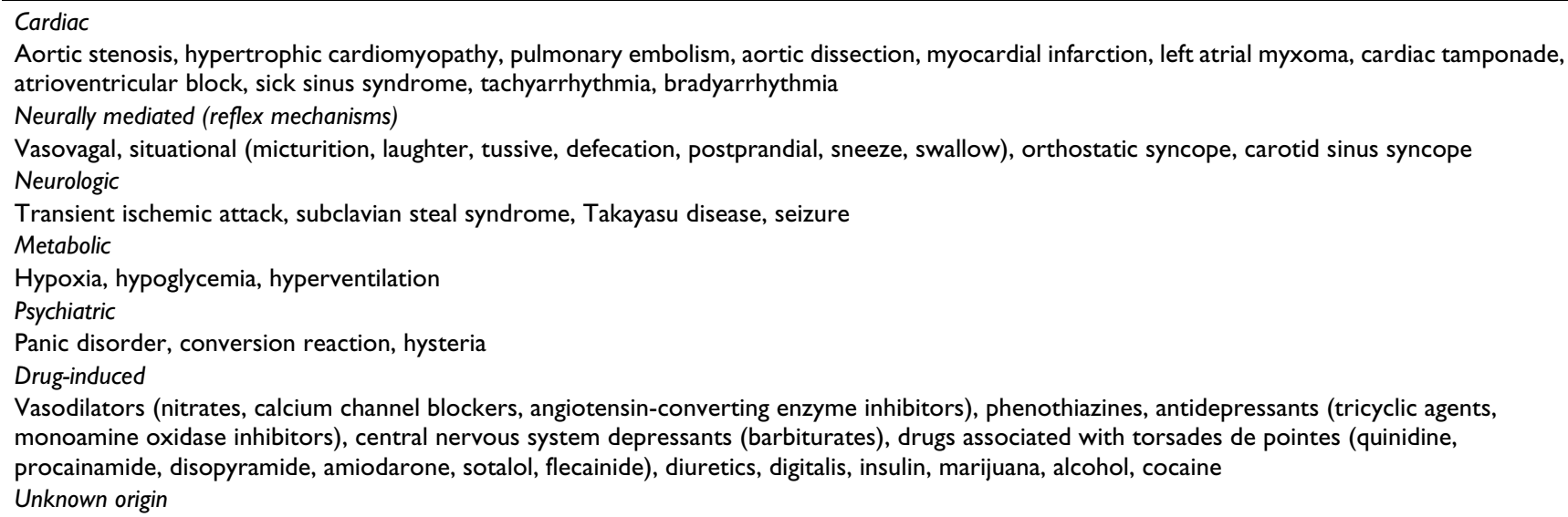

acute vascular dilatation, thereby exacerbating the reduction in venous return [3].

Normally the body is able to compensate for these changes through cerebral vascular autoregulation and autonomic reflexes. In one of the most well-known reflex arcs, reduced cardiac output leads to decreased stimulation of carotid sinus and aortic arch baroreceptors, as well as mechanoreceptors in the left ventricle wall [4]. The resulting increase in sympathetic tone maintains blood pressure for adequate cerebral perfusion. However, in neurally mediated syncopes, there is acute and inappropriate hypotension and bradycardia exacerbating the reduction in cerebral perfusion, resulting in a transient loss of consciousness. It is hypothesized that increased ventricular contraction in response to reduced venous return stimulates the left ventricle mechanoreceptors to a degree that is able to override the baroreceptor reflex and cause an inappropriate increase in parasympathetic tone [4]. Aside from laughter-induced syncope, this mechanism is also thought to account for syncope secondary to coughing, sneezing and other Valsalva-related activities.

To the best of the authors' knowledge, only five cases of laugh syncope among adults have been reported in the literature [3,5-8] (Table 2). We present the case of a 56-yearold man who suffered from syncope secondary to intense laughter.

\section{Case presentation}

A 56-year-old, moderately obese (body mass index of 35) man with a past medical history of sleep apnea, hypertension and hyperlipidemia presented to his primary care physician for routine health maintenance. He mentioned that he had recently been very busy with overtime work, which had left him exhausted. He informed the physician of an incident that occurred one evening as he entertained his colleagues in a fine restaurant. While waiting for the meals to be served, a guest had told a very amusing joke and the patient began to laugh heartily, "Ha, ha, ha, ha... " in decrescendo until he was out of breath. To everyone's surprise, he then fell forward resting his head on the table and remained unresponsive for a few seconds before regaining consciousness. Prior to losing consciousness, he described feeling short of breath and noted that his surroundings were becoming dark. No seizure-like activity or incontinence was witnessed. After the episode he denied nausea, diaphoresis or otherwise feeling sick and proceeded to eat when his entrée was served. The remainder of the evening was without incident.

He had a history of syncope in the distant past in which he had collapsed on the floor for several seconds following hours of overtime work. Treadmill stress testing after the incident revealed no arrhythmia or ischemic disease, although he complained of dizziness after the test and a sudden drop in blood pressure was noted. At the time, he had been in poor physical condition with a sedentary lifestyle. He was encouraged to exercise and remained free of symptoms until this episode.

\section{Discussion and conclusion}

Laugh syncope was diagnosed in the patient based on his characteristic presentation. Situational syncopes such as laugh syncope are usually diagnosed using history from the patient [9]. In the other known cases of laugh syncope reported in the literature, more thorough and extensive diagnostic evaluations were performed [3,5-8]. However, all cases had a common characteristic history of transient loss of consciousness following intense laughter, which potentially could have obviated the need for an expensive diagnostic evaluation. The burden of syncope evaluation on the health care budget is significant. It has been estimated that hospital admission of patients presenting with 
Table 2: Reported cases of laugh syncope among adults

\begin{tabular}{lllll}
\hline Reference & Age (years) & Sex & Predisposing factor & Recurrence \\
\hline$[3]$ & 62 & Male & Brachiocephalic stenosis & Yes (prior to stent placement) \\
{$[5]$} & 32 & Male & None & No \\
{$[6]$} & 60 & Male & Hypovolemia & No \\
{$[7]$} & 63 & Male & None & Yes \\
{$[8]$} & 55 & Male & None & No \\
\hline
\end{tabular}

syncope for inpatient evaluation costs the health care system more than US $\$ 2.4$ billion dollars per year in the USA [10].

To date, numerous causes of syncope have been recognized (Table 1). This presents a diagnostic challenge to clinicians. In the initial evaluation of syncope patients, the diagnostic rate is estimated to be only $20 \%$ to $50 \%$ [1]. Even after extensive diagnostic work-up, no cause can be identified in $15 \%$ to $30 \%$ of patients [1]. There is no diagnostic 'gold standard' for syncope. A careful history, physical examination and electrocardiogram (ECG) are usually the most efficacious means used to establish a diagnosis or determine the need for further diagnostic testing [11]. Unlike history and physical examination, ECG actually has a low diagnostic yield [1]. It should be included in the initial syncope evaluation, however, because it is noninvasive, relatively inexpensive and can detect potentially life-threatening conditions. Extensive laboratory and imaging studies rarely provide useful diagnostic information unless specifically indicated. Unfortunately, the evaluation of patients presenting with syncope is frequently unable to reveal a clear etiology and many cases remain unexplained.

With syncope patients, emergency physicians are often confronted with the difficult decision of whether the patient should be admitted for inpatient evaluation and management. Syncope patients are frequently admitted following an initial non-diagnostic evaluation because of concerns of underlying life-threatening conditions (for example, dysrhythmias, pulmonary embolism or acute coronary syndrome) or belief that inpatient evaluation will reveal the cause [12]. So the question of who should be hospitalized for syncope remains. As noted previously, the diagnostic yield of extensive work-up is relatively poor. The focus in syncope evaluation, therefore, has shifted from attempting to make a specific diagnosis to risk stratification. Through careful risk stratification, it is hoped that health care resources will be more efficiently allocated to those patients most at risk of serious outcome and, hence, more likely to benefit from inpatient care. In a recent update of their 2001 clinical policy on syncope, the American College of Emergency Physicians emphasized the use of history, physical examination and stand- ard 12-lead ECG to risk-stratify patients and admit those with risk factors for adverse outcome such as heart failure, coronary artery disease, structural heart disease, older age, concurrent comorbidities, hematocrit less than 30\% (if obtained) or abnormal ECG [1].

Several other studies have also developed clinical decision rules to aid in the risk stratification of syncope patients. The San Francisco Syncope Rule (SFSR) has been shown to be sensitive in identifying patients at risk of serious outcome within 7 days of initial emergency department presentation based on the following predictors: abnormal ECG, shortness of breath, systolic blood pressure under $90 \mathrm{~mm} \mathrm{Hg}$, hematocrit less than 30\% and congestive heart failure by history or examination [13]. However, another external validation cohort found that the SFSR had a lower sensitivity and specificity than reported previously suggesting that the rule may require further validation before it can be applied safely in clinical practice [14].

The prognosis for patients presenting with syncope varies according to the underlying etiology. One populationbased study found that cardiac and neurologic syncope were associated with an increased risk of death from any cause and an increased risk of cardiovascular events and stroke, respectively [15]. By comparison, patients with vasovagal, orthostatic, medication-induced and situational syncope had no increase in the risk of death from any cause compared with patients without syncope [15]. Although laugh syncope was not specifically addressed in this study, as a type of situational syncope, we extrapolate that its prognosis is likely benign. To the best of our knowledge, no study to date has investigated the prognosis of laugh syncope.

\section{Abbreviations}

ECG: electrocardiogram; SFSR: San Francisco Syncope Rule.

\section{Competing interests}

The authors declare that they have no competing interests.

\section{Consent}

Written informed consent was obtained from the patient for publication of this case report. A copy of the written 
consent is available for review by the Editor-in-Chief of this journal.

\section{Authors' contributions}

$\mathrm{KN}$ and SKH drafted the manuscript, JT cared for the patient, performed the investigation that led to the patient's diagnosis and assisted in the formulation of the manuscript. All authors read and approved the final manuscript.

\section{References}

I. Huff JS, Decker WW, Quinn JV, Perron AD, Napoli AM, Peeters S, Jagoda AS: Clinical policy: critical issues in the evaluation and management of adult patients presenting to the emergency department with syncope. J Emerg Nurs 2007, 33:e I-el 7.

2. Alboni P, Brignole M, Menozzi C, Raviele A, Del Rosso A, Dinelli M, Solano A, Bottoni N: Diagnostic value of history in patients with syncope with or without heart disease. J Am Coll Cardiol 200I, 37:192I-1928.

3. Bragg MJ: Fall about laughing: a case of laughter syncope. Emerg Med Australas 2006, 18:518-519.

4. Arthur W, Kaye GC: Important points in the clinical evaluation of patients with syncope. Postgrad Med J 2001, 77:99-102.

5. Cox SV, Eisenhauer AC, Hreib K: "Seinfeld syncope". Cathet Cardiovasc Diagn 1997, 42:242.

6. Bloomfield D, Jazrawi $S$ : Shear hilarity leading to laugh syncope in a healthy man. JAMA 2005, 293:2863-2864.

7. Sarzi Braga S, Manni R, Pedretti RF: Laughter-induced syncope. Lancet 2005, 366:426.

8. Totah AR, Benbadis SR: Gelastic syncope mistaken for cataplexy. Sleep Med 2002, 3:77-78.

9. Kapoor WN: Evaluation and management of the patient with syncope. JAMA 1992, 268:2553-2560.

10. Sun BC, Emond JA, Camargo CA Jr: Direct medical costs of syncope-related hospitalizations in the United States. Am J Cardiol 2005, 95:668-67I.

II. Linzer M, Yang EH, Estes NA III, Wang P, Vorperian VR, Kapoor WN: Diagnosing syncope. Part I: Value of history, physical examination, and electrocardiography. Clinical Efficacy Assessment Project of the American College of Physicians. Ann Intern Med 1997, I 26:989-996.

12. Morag RM, Murdock LF, Khan ZA, Heller MJ, Brenner BE: Do patients with a negative Emergency Department evaluation for syncope require hospital admission? J Emerg Med 2004, 27:339-343.

13. Quinn J, McDermott D, Stiell I, Kohn M, Wells G: Prospective validation of the San Francisco Syncope Rule to predict patients with serious outcomes. Ann Emerg Med 2006, 47:448-454.

14. Sun BC, Mangione CM, Merchant G, Weiss T, Shlamovitz GZ, Zargaraff G, Shiraga S, Hoffman JR, Mower WR: External validation of the San Francisco Syncope Rule. Ann Emerg Med 2007, 49:420-427. e42I-424.

15. Soteriades ES, Evans JC, Larson MG, Chen MH, Chen L, Benjamin EJ, Levy D: Incidence and prognosis of syncope. N Engl J Med 2002, 347:878-885.
Publish with Biomed Central and every scientist can read your work free of charge

"BioMed Central will be the most significant development for disseminating the results of biomedical research in our lifetime. "

Sir Paul Nurse, Cancer Research UK

Your research papers will be:

- available free of charge to the entire biomedical community

- peer reviewed and published immediately upon acceptance

- cited in PubMed and archived on PubMed Central

- yours - you keep the copyright

Submit your manuscript here:

http://www.biomedcentral.com/info/publishing_adv.asp
BioMedcentral 